\title{
ORIGINAL
}

\section{Antenatal management of recurrent fetal goitrous hyperthyroidism associated with fetal cardiac failure in a pregnant woman with persistent high levels of thyroid- stimulating hormone receptor antibody after ablative therapy}

\author{
Tadashi Matsumoto ${ }^{1)}$, Kei Miyakoshi ${ }^{1)}$, Yoshifumi Saisho ${ }^{2)}$, Tomohiro Ishii ${ }^{3)}$, Satoru Ikenoue ${ }^{1)}$, \\ Yoshifumi Kasuga ${ }^{1)}$, Ikuko Kadohira ${ }^{1)}$, Seiji Sato ${ }^{1)}$, Naoko Momotani ${ }^{4)}$, Kazuhiro Minegishi ${ }^{1)}$ \\ and Yasunori Yoshimura ${ }^{1)}$ \\ ${ }^{1)}$ Department of Obstetrics and Gynecology, Keio University, School of Medicine, Tokyo 160-8582, Japan \\ ${ }^{2)}$ Department of Internal Medicine, Keio University, School of Medicine, Tokyo 160-8582, Japan \\ ${ }^{3)}$ Department of Pediatrics, Keio University, School of Medicine, Tokyo 160-8582, Japan \\ 4) Department of Endocrinology, Tokyo Health Service Association, Tokyo 162-8402, Japan
}

\begin{abstract}
High titer of maternal thyroid-stimulating hormone receptor antibody (TRAb) in patients with Graves' disease could cause fetal hyperthyroidism during pregnancy. Clinical features of fetal hyperthyroidism include tachycardia, goiter, growth restriction, advanced bone maturation, cardiomegaly, and fetal death. The recognition and treatment of fetal hyperthyroidism are believed to be important to optimize growth and intellectual development in affected fetuses. We herein report a case of fetal treatment in two successive siblings showing in utero hyperthyroid status in a woman with a history of ablative treatment for Graves' disease. The fetuses were considered in hyperthyroid status based on high levels of maternal TRAb, a goiter, and persistent tachycardia. In particular, cardiac failure was observed in the second fetus. With intrauterine treatment using potassium iodine and propylthiouracil, fetal cardiac function improved. A high level of TRAb was detected in the both neonates. To the best of our knowledge, this is the first report on the changes of fetal cardiac function in response to fetal treatment in two siblings showing in utero hyperthyroid status. This case report illustrates the impact of prenatal medication via the maternal circulation for fetal hyperthyroidism and cardiac failure.
\end{abstract}

Key words: Graves' disease, Fetal hyperthyroidism, Fetal goiter, Prenatal diagnosis, Fetal therapy

\begin{abstract}
ANTIBODIES to the thyroid-stimulating hormone receptor (TRAb), like other IgG, do not cross the placenta until 16 weeks and, therefore, could not play a role in early thyroid embryogenesis [1]. However, after 17 weeks gestation, since TRAb cross the placenta and fetal thyroid gland also develops, patients with Graves' disease showing high titer of TRAb might have adverse impact on fetal and neonatal outcomes including hyperthyroidism, non-immune fetal hydrops, and growth restriction [2]. We herein described a case of successful management of fetal cardiac failure com-

Submitted Jun. 13, 2013; Accepted Aug. 12, 2013 as EJ13-0248 Released online in J-STAGE as advance publication Sep. 11, 2013 Correspondence to: Tadashi Matsumoto, M.D., Department of Obstetrics and Gynecology, Keio University, School of Medicine, 35 Shinanomachi, Shinjuku-ku, Tokyo 160-8582, Japan.

E-mail: tmatsumoto@a2.keio.jp

(C)The Japan Endocrine Society
\end{abstract}

plicated by fetal goitrous hyperthyroidism associated with persistent high levels of maternal TRAb in a pregnant woman with Graves' disease in hypothyroid status treated with thyroid hormone replacement after subtotal thyroidectomy and radioiodine therapy. Our experience would be significant information on perinatal management in women with Graves' disease presenting high levels of TRAb.

\section{Materials and Methods}

\section{Measurements of thyroid hormone and TRAb}

$\mathrm{TSH}$, free T4 (fT4), and free T3 (fT3) were measured using an electro chemiluminescence immunoassay (ECLIA) with the Cobas ECLIA kits (Roche Diagnostics, Japan). The values were interpreted according to gestational or postnatal age [3]. TRAb were measured 
by ECLIA with third-generation assay using anti TSH receptor monoclonal antibody (M22) (Elecsys anti-TSH receptor assay (Roche Diagnostics $\mathrm{GmbH}$, Penzberg, Germany)) [4]. A positive result was defined as an antibody titer greater than or equal to $2.0 \mathrm{IU} / \mathrm{L}$.

\section{Assessment of fetal cardiac function}

ACUSON Antares (Siemens Medical Solutions, Mountain View, CA, USA) ultrasound system equipped with a CH6-2 transducer (2-6 MHz) was used to evaluate fetal cardiac function. M-mode sonography or cardiotocography tracings were used commonly to measure baseline fetal heart rate. Current international guidelines recommend for the normal fetal heart rate baseline different ranges of 110 to $160 \mathrm{bpm}$. If the baseline rate is greater than $160 \mathrm{bpm}$, it is termed tachycardia [5]. The preload indexes (PLIs) and cardiothoracic area ratios (CTARs) were analyzed on the second fetus showing in utero hyperthyroid status. CTARs was defined as the ratio of the cardiac area to the thoracic area in the four-chamber view of the heart in diastole [6]. Less than $35 \%$ CTAR is normal regardless of gestational age, whereas cardiomegaly was defined as CTAR greater than or equal to $35 \%$. The inferior vena cava (IVC) waveform of human fetuses has a pulsatile pattern comprising 3 phases, namely, reversed flow during atrial contraction (A), early forward flow coinciding with atrial diastole and ventricular systole (Sf), and late forward flow coinciding with ventricular diastole (Df). The PLIs-IVC is the ratio of the peak velocity of A to the peak velocity of Sf, and the value of this parameter increases under high preload conditions. In normal fetuses, PLIs-IVC values range from 0 to 0.37 and have no relation with gestational age [7].

\section{Case Report}

A 30-year-old-Japanese woman, gravida 1, para 0 , was referred to the high-risk prenatal care unit in our hospital because of fetal tachycardia at 23 weeks of gestation. Obstetric ultrasound examination revealed an anterior fetal neck mass, which was bilobed, symmetrical, solid, and measuring $17 \times 9 \mathrm{~mm}$ (Fig. 1). The fetal heart rate was around $170 \mathrm{bpm}$. No other structural abnormalities were noted and the amniotic fluid volume was within normal range. The mother had a history of Graves' disease and received medical therapy, followed by subtotal thyroidectomy and radioiodine therapy. As a result of those treatments, she developed hypothyroidism and levothyroxine (LT4) replacement was started. Until the mid-second trimester, she had been euthyroid with LT4 replacement therapy, although high titer of TRAb persisted. It was noted that she showed marked bilateral periorbital edema and exophthalmos. Her thyroid functions at 23 weeks of gestation were as follows: TRAb $381 \mathrm{IU} / \mathrm{L}$ [manufacture reference range: $<2.0 \mathrm{IU} / \mathrm{L}$ ], TSH $0.09 \mu \mathrm{U} / \mathrm{mL}$ [manufacture reference range: $0.3-4.5 \mu \mathrm{U} / \mathrm{mL}$ ], free thyroxine (fT4) $1.7 \mathrm{ng} / \mathrm{dL}$ [manufacture reference range: $0.7-1.8 \mathrm{ng} / \mathrm{dL}$ ], free triiodothyronine (fT3) $2.7 \mathrm{pg} / \mathrm{mL}$ [manufacture reference range: $2.0-4.5 \mathrm{pg} / \mathrm{mL}$ ] (Table 1a). Based on these clinical findings, the fetus was diagnosed as having hyper-
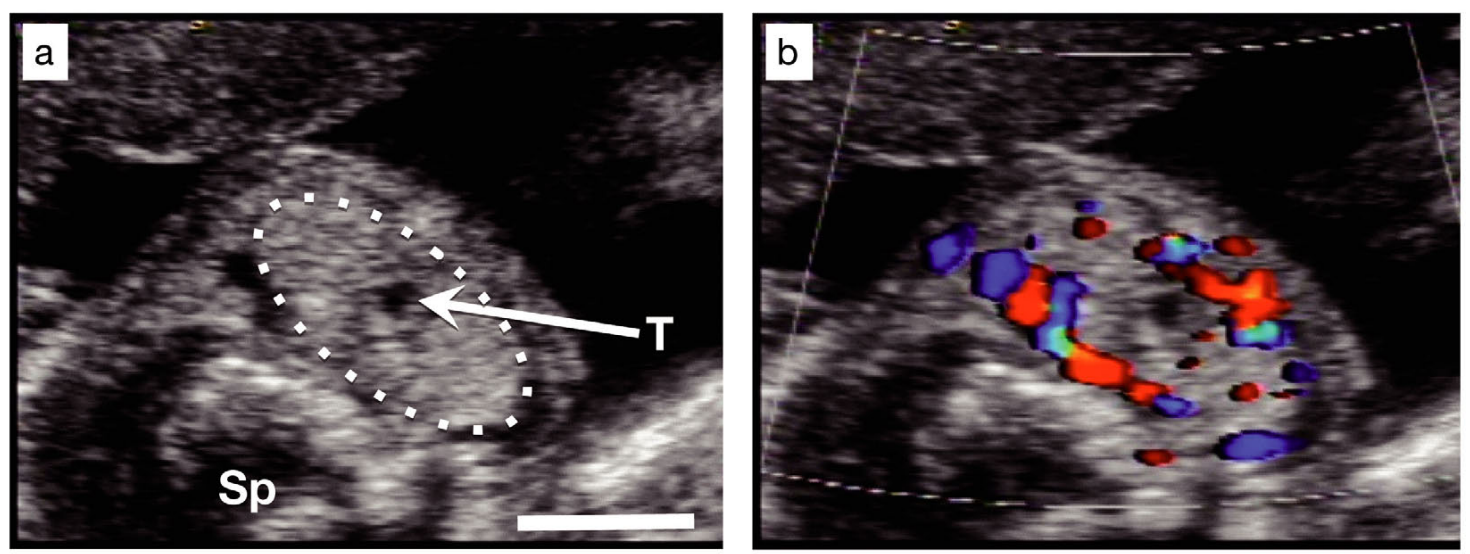

Fig. 1 Sonographic features of a fetal goitor a. Transverse view of the fetal neck at 23 weeks gestation showing the thyroid mass located within the region of the ellipse. The trachea $(\mathrm{T})$ is shown in the middle of the mass. $\mathrm{Sp}=$ spine. Bar=10mm

b. Color-flow Doppler imaging demonstrating the mass surrounded by abundant blood flow. 
thyroidism. Because she had a history of eruption with use of methimazole (MMI), oral maternal potassium iodide (KI) $(50 \mathrm{mg} /$ day) and propylthiouracil (PTU: $150 \mathrm{mg}$ /day) was initiated as in utero treatment for fetal hyperthyroidism. Since fetal heart rate didn't dropped and remained between 160 and $180 \mathrm{bpm}$, the dosage of PTU gradually increased up to $300 \mathrm{mg}$ at 34 weeks of gestation. During the follow-up, fetal growth restriction, defined as sonographic estimated fetal weight $<$ $-1.5 \mathrm{SD}$, became remarkable as pregnancy progressed, however, fetus did not develop cardiac failure and the heart rate was within normal range (141 bpm) after 35 weeks of gestation. At 36 weeks of gestation, a male neonate weighing $1,966 \mathrm{~g}$ was delivered by cesarean section because of possible dystocia due to enlarged fetal thyroid gland and non-reassuring fetal status. His Apgar scores at $1 \mathrm{~min}$ and $5 \mathrm{~min}$ were 8 and 9, respectively. On the day of birth, his thyroid gland was obviously enlarged and blood examination showed suppressed level of TSH (TRAb 445.0 IU/L [normal: $<2.0 \mathrm{IU} / \mathrm{L}$ ], TSH $0.01 \mu \mathrm{U} / \mathrm{mL}$ [normal: $1.0-20.0 \mu \mathrm{U} /$ $\mathrm{mL}$ ], fT4 $0.9 \mathrm{ng} / \mathrm{dL}$ [normal: 2.0-5.0 ng/dL], fT3 4.3 $\mathrm{pg} / \mathrm{mL}$ [normal: 2.0-6.1 pg/mL], TSAb $2470 \%$ [normal: $<180 \%$ ]) (Table 1b) [reference ranges for neo-

Table 1a Maternal Thyroid Status

\begin{tabular}{|c|c|c|c|c|c|c|c|c|}
\hline & \multirow{2}{*}{$\begin{array}{l}\text { Gestational } \\
\text { weeks }\end{array}$} & \multirow{2}{*}{$\begin{array}{l}\text { TRAb } \\
{[\text { IU/L] }} \\
(<2.0)\end{array}$} & \multirow{2}{*}{$\begin{array}{c}\text { TSH } \\
{[\mu \mathrm{U} / \mathrm{mL}]}\end{array}$} & \multirow{2}{*}{$\begin{array}{c}\mathrm{fT} 4 \\
{[\mathrm{ng} / \mathrm{dL}]} \\
(0.7-1.8)\end{array}$} & \multirow{2}{*}{$\begin{array}{c}\mathrm{fT} 3 \\
{[\mathrm{pg} / \mathrm{mL}]} \\
(2.0-4.5)\end{array}$} & \multicolumn{3}{|c|}{ Maternal treatment (/day) } \\
\hline & & & & & & LT4 & PTU & $\mathrm{KI}$ \\
\hline \multirow{4}{*}{$\begin{array}{c}\text { 1st } \\
\text { pregnancy }\end{array}$} & pre gestation & - & $4.40(0.3-4.5)$ & 1.00 & - & $100 \mu \mathrm{g}$ & - & - \\
\hline & 23 & 381.0 & $0.09(0.2-3.0)$ & 1.7 & 2.7 & $150 \mu \mathrm{g}$ & $150 \mathrm{mg}$ & $50 \mathrm{mg}$ \\
\hline & 36 & 397.0 & $1.07(0.3-3.0)$ & 1.3 & 2.1 & $150 \mu \mathrm{g}$ & $300 \mathrm{mg}$ & $50 \mathrm{mg}$ \\
\hline & postpartum 1 month & 424.0 & $0.21(0.3-4.5)$ & 1.5 & 3.2 & $100 \mu \mathrm{g}$ & - & - \\
\hline \multirow{5}{*}{$\begin{array}{l}\text { 2nd } \\
\text { pregnancy }\end{array}$} & pre gestation & 230.0 & $4.16(0.3-4.5)$ & 1.7 & 1.8 & $100 \mu \mathrm{g}$ & - & - \\
\hline & 10 & 230.0 & $0.09(0.1-2.5)$ & 1.7 & 2.7 & $150 \mu \mathrm{g}$ & - & - \\
\hline & 21 & 223.0 & $0.10(0.2-3.0)$ & 1.8 & 3.6 & $150 \mu \mathrm{g}$ & $300 \mathrm{mg}$ & $50 \mathrm{mg}$ \\
\hline & 34 & 221.0 & $1.92(0.3-3.0)$ & 1.5 & 2.3 & $150 \mu \mathrm{g}$ & $300 \mathrm{mg}$ & $100 \mathrm{mg}$ \\
\hline & postpartum 1 month & 223.0 & $0.30(0.3-4.5)$ & 1.9 & 3.5 & $100 \mu \mathrm{g}$ & - & - \\
\hline
\end{tabular}

Normal range is shown in parenthesis.

The mother having a history of Graves' disease and received medical therapy was euthyroid status with levothyroxine replacement therapy, however, high titer of TRAb was persisted through two times of gestational period. TSH, thyroidstimulating hormone (thyrotropin); TRAb, TSH receptor antibody; fT4, free thyroxine; fT3, free triodothyronine; LT4, levothyroxine; PTU, propylthiouracil; KI, potassium iodide

Table 1b Neonatal Thyroid Statuses

\begin{tabular}{cccccc}
\hline & $\begin{array}{c}\text { thyroid status } \\
\text { of each sibling }\end{array}$ & $\begin{array}{c}\text { TRAb } \\
{[\mathrm{IU} / \mathrm{L}]}\end{array}$ & $\begin{array}{c}\text { TSH } \\
{[\mu \mathrm{U} / \mathrm{mL}]}\end{array}$ & $\begin{array}{c}\mathrm{fT} 4 \\
{[\mathrm{ng} / \mathrm{dL}]}\end{array}$ & $\begin{array}{c}\mathrm{fT} 3 \\
{[\mathrm{pg} / \mathrm{mL}]}\end{array}$ \\
\hline \multirow{2}{*}{$\begin{array}{c}\text { 1st } \\
\text { pregnancy }\end{array}$} & day 0 & $445.0(<2.0)$ & $0.01(1.0-20.0)$ & $0.9(2.0-5.0)$ & $4.3(2.0-6.1)$ \\
& day 36 & - & $<0.01(0.5-6.5)$ & $0.8(0.9-2.2)$ & $3.8(2.4-5.6)$ \\
\multirow{2}{*}{$\begin{array}{c}\text { 2nd } \\
\text { pregnancy }\end{array}$} & day 0 & $120.0(<2.0)$ & $0.01(1.0-20.0)$ & $1.4(2.0-5.0)$ & $4.9(2.0-6.1)$ \\
& day 15 & - & $<0.01(0.5-6.5)$ & $0.7(0.9-2.2)$ & $4.2(2.4-5.6)$ \\
\hline
\end{tabular}

Normal range is shown in parenthesis.

Laboratory examination of both neonates showed hyperthyroid status, and MMI was initiated immediately after birth. Levothyroxine replacement was implemented on Day 36 of 1st neonates and on Day 15 of 2nd neonates because the neonates showed central hypothyroidism. TSH, thyroid-stimulating hormone (thyrotropin); TRAb, TSH receptor antibody; fT4, free thyroxine; fT3, free triodothyronine 
natal thyroid status according to Kliegman et al. [8]]. The neonatal hyperthyroidism manifested with tachycardia (140-180 bpm), prompting administration of 2 mg of MMI immediately after birth. In addition, on Day 17, $4 \mathrm{mg}$ of atenolol was also started for persistent tachycardia. Thereafter, MMI and atenolol were discontinued at 8 weeks of age. LT4 replacement was implemented on Day 36 because of central hypothyroidism and the infant received LT4 replacement therapy until 2 years of age, when the hypothyroidic state resolved [9]. Follow-up examination at the age of two showed the failure to thrive. He weighted $8.2 \mathrm{~kg}(<5$ th percentile) and was $77 \mathrm{~cm}$ tall ( $<5$ th percentile).

Two years after the first delivery, she became pregnant again. When first seen at 10 weeks of gestation, she was euthyroid under the LT4 replacement therapy, as follows: TRAb 230.0 IU/L, TSH $0.09 \mu \mathrm{U} / \mathrm{mL}$, fT4 $1.7 \mathrm{ng} / \mathrm{dL}$, fT3 $2.7 \mathrm{pg} / \mathrm{mL}$ (Table 1a). Obstetric ultrasound showed appropriate-for-date fetus with no abnormalities and the pregnancy course was uneventful. At 21 weeks of gestation, however, the fetus developed baseline tachycardia over $170 \mathrm{bpm}$. Fetal ultrasound examination revealed an enlarged thyroid gland $(15 \times 12 \mathrm{~mm})$, pericardial effusion and cardiomegaly (Fig. 2a). Additionally, at 22 weeks of gestation, CTAR and PLI of the inferior vena cava were $53 \%$ and 0.94 , respectively. Taken together, the fetus was diagnosed to have in utero cardiac failure associated with hyperthyroidism. Based on the clinical course in the first pregnancy, oral maternal potassium iodide $(50 \mathrm{mg} /$ day $)$ and
PTU (300 mg/day) were initiated (Fig. 3). At 24 weeks of gestation, pericardial effusion resolved. In addition, the CTAR as well as the PLI gradually improved to $46 \%$ and 0.72 after the initiation of fetal treatment. Since the PLI was still elevated and persistent fetal tachycardia $(160 \mathrm{bpm})$ was seen at 30 weeks of gestation, oral maternal potassium iodide increased to $100 \mathrm{mg}$ /day. Finally, fetal tachycardia and cardiomegaly resolved at the 34 weeks gestation (Fig. 2b), however, the enlarged thyroid gland was still present (Fig. 4) and the circumference of the thyroid was $9.8 \mathrm{~cm}$ [normal: $3.7 \sim 6.0 \mathrm{~cm}$ ] [reference ranges for fetal thyroid size according to Ranzini AC et al. [10]]. Subsequently, because preterm premature rapture of the membrane occurred at 35 weeks gestation, the mother delivered a 2034-g female neonate by repeated cesarean, with Apgar scores of 8 and 9 at 1 and $5 \mathrm{~min}$, respectively. Laboratory examination on Day 0 showed neonatal subclinical hyperthyroidism (TRAb $120.0 \mathrm{IU} / \mathrm{L}, \mathrm{TSH} 0.01 \mu \mathrm{U} / \mathrm{mL}$, fT4 1.4 $\mathrm{ng} / \mathrm{dL}$, fT3 $4.9 \mathrm{pg} / \mathrm{mL}$ ) (Table 1b). Moreover, because the electrocardiogram of the baby after birth showed persistent tachycardia and accelerated maturation of the femoral ossification center was seen, MMI was initiated immediately after birth. Similar to her sibling, LT4 replacement was performed for possible central hypothyroidism. At 7 months of age, the neonate showed growth and gross motor developmental delays. She weighted $5.7 \mathrm{~kg}(<5$ th percentile) and was $62 \mathrm{~cm}$ tall $(<5$ th percentile), and she wasn't able to sit without support and to crawl.
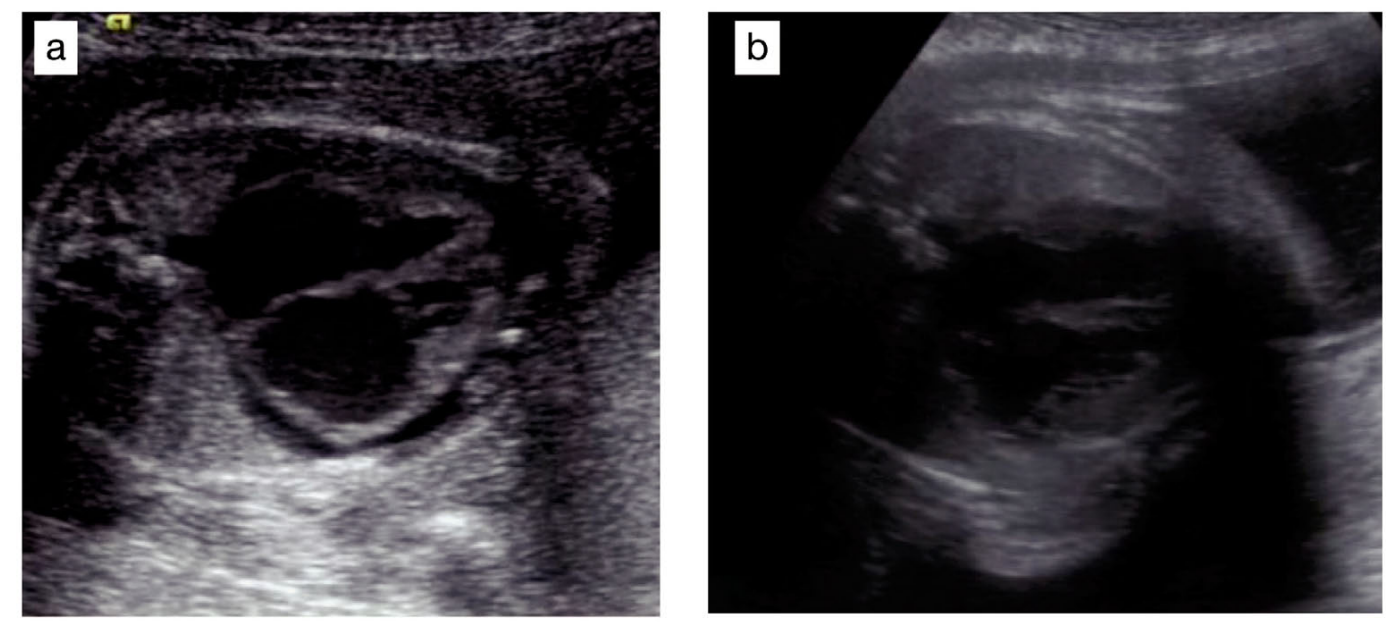

Fig. 2 Sonographic cross-sectional view of fetal thorax

a. Note fetal cardiomegaly with pericardial effusion at 21 weeks gestation.

b. Note cardiomegaly resolved at 34 weeks gestation by in utero treatment. 


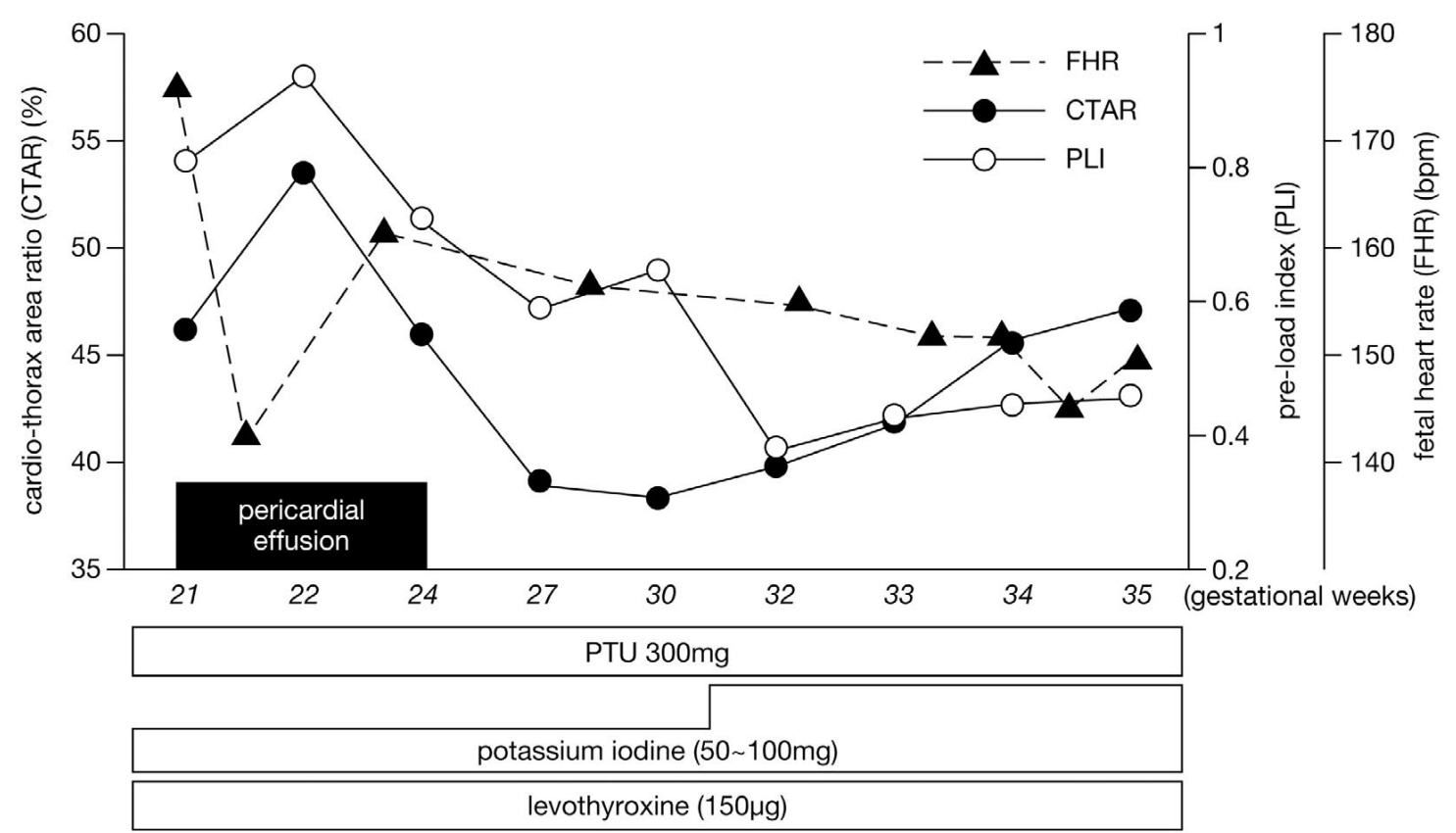

Fig. 3 Changes in sonographic measurements for fetal cardiac function

The cardio-thorax area ratio (CTAR) and pre-load index (PLI) of the inferior vena cava improved after the initiation of in utero treatment. Potassium iodide was increased up to $100 \mathrm{mg} /$ day because of persistent fetal tachycardia.

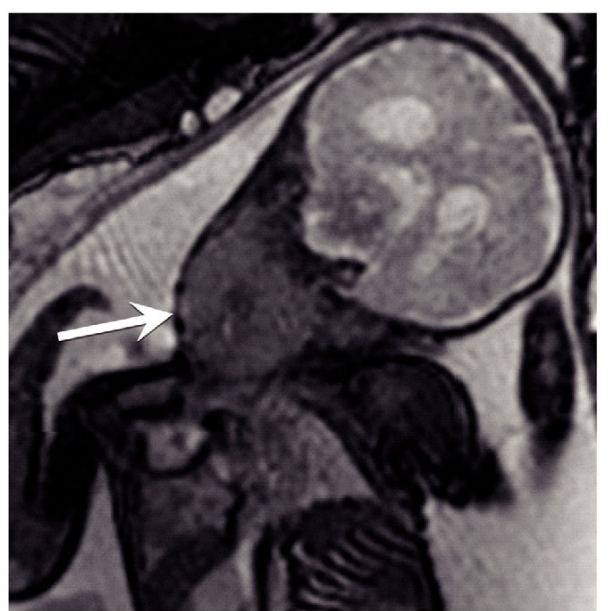

Fig. 4 Fetal magnetic resonance imaging Note the enlarged thyroid gland showing heterogeneous intensity on the T2-weighted imaging (arrow).

\section{Discussion}

In our case, the mother with a history of Graves' disease showed persistent high levels of maternal TRAb, although she was in a hypothyroidic state being treated with LT4 replacement therapy after subtotal thyroidectomy and radioiodine therapy. Our case was significant in that 1) fetal hyperthyroidism was diagnosed based on the clinical features, 2) fetal treatment using oral maternal anti-thyroid medicines was effective for improving cardiac failure, 3) maternal TRAb contributed to the development of fetal and neonatal hyperthyroidism.

Cordocentesis allows direct and accurate evaluation of the fetal endocrine status, however, most concern is the procedure-related complications including transient bleeding at puncture site, transient fetal bradycardia, chorioamnionitis, and cord hematoma [11]. In this case, high serum levels of maternal TRAb values as well as fetal sonographic features led us to the diagnosis of fetal hyperthyroidism, which was confirmed after birth. Therefore, fetal hyperthyroidism could be diagnosed without the invasive procedures (i.e. cordocentesis). In particular, the key feature for the suspicion of fetal hyperthyroidism might be persistent tachycardia in women with Graves' disease, as was shown in previous reports [12].

Fetal treatment using oral maternal potassium iodide and PTU was performed in our patient. Especially, PTU is preferred to MMI during the first trimester because the latter has been associated with aplasia cutis congenital and other malformation $[12,13]$. In our case, the patient received PTU because of a history of allergic symptoms to MMI. Potassium iodide acutely inhibits hormonal secretion within hours in hyperthyroid 
patients [14]. The reason for our choice of potassium iodide in combination with PTU was that 1) iodine has few side effects, 2) iodine has prompt therapeutic effects, and 3) the urgent treatment was needed for fetus in hyperthyroid status $[15,16]$.

Our report demonstrated changes in fetal cardiac function in response to oral maternal anti-thyroid medicine. Based on the indices (i.e. PLI and CTAR), we have adjusted the dosage of potassium iodide and PTU during treatment. In pregnant patients with active Graves' hyperthyroidism, it is well established that fetuses can be maintained euthyroid by keeping maternal FT4 in the upper normal to mildly thyrotoxic range for pregnant women [17]. However, there has been no safe and reliable method of determining fetal thyroid function due to the lack of monitoring maternal thyroid function. Morine et al. have shown the usefulness of sonographic measurements to gain insights into the pathophysiology of cardiac failure associated with fetal goitrous hypothyroidism [18]. Our results suggest both PLI and CTAR could contribute to the appropriate follow-up in fetal hyperthyroidism. In this case, although fetal cardiac functions were well controlled in both fetuses, the both neonates showed developmental delay at the age of two years and 7 months, respectively. The reason for this discrepancy remained unknown, but could be due to the association with fetal hyperthyroidism or other abnormalities, since both fetuses already showed growth restriction in utero. The clinical features of fetal hyperthyroidism were less severe in the first fetus than in the second, but higher levels of maternal and neonatal TRAb were noted in the first pregnancy. Reports of outcomes in siblings born to a mother with Graves' disease after total thyroidectomy or radioiodine treatment are limited. Hamada et al. demonstrated that the occurrence of neonatal hyperthyroidism is not only due to high levels of TRAb before pregnancy, but also to TRAb not decreasing during pregnancy [19]. Additionally, fetal thyroid function might depend on the balance between the transplacental passage of maternal TRAb and thyroid inhibiting antithyroid drugs [20]. Thus, it seems difficult to predict fetal and/or neonatal outcome in Graves' disease with high levels of TRAb.

In conclusion, when managing pregnant women with complicated Graves' disease, it should be remembered that two patients are being treated: the mother and the fetus. Especially, women with history of surgery or radioiodine therapy are at risk for fetal hyperthyroidism. To the best of our knowledge, this is the first report on the changes of fetal cardiac function in response to the fetal treatment in two siblings showing in utero hyperthyroid status. The fetal heart rate and sonographic parameters for cardiac function could be useful in indicating the onset of hyperthyroidism and monitoring a response to therapy.

\section{Disclosure Statement}

The authors declare that no competing financial interests exist.

\section{Acknowledgement}

The authors acknowledge medical staffs in the perinatal unit of Keio University Hospital for excellent patient care. The authors have no conflict of interest associated with this manuscript. We thank Ms. Melinda Murphy for her helpful suggestions in preparing the manuscript.

\section{References}

1. McKenzie JM, Zakarija M (1992) Fetal and neonatal hyperthyroidism and hypothyroidism due to maternal TSH receptor antibodies. Thyroid 2:155-159.

2. Zimmerman D (1999) Fetal and neonatal hyperthyroidism. Thyroid 9: 727-733.

3. Stagnaro-Green A, Abalovich M, Alexander E, et al. (2011) Guidelines of the American Thyroid Association for the diagnosis and management of thyroid disease during pregnancy and postpartum. Thyroid 21:1081-1125.

4. Kamijo K, Ishikawa K, Tanaka M (2005) Clinical evaluation of 3rd generation assay for thyrotropin receptor antibodies: the M22-biotin-based ELISA initiated by Smith. Endocr J 52: 525-529.

5. National Institute of Child Health and Human Development Research Planning Workshop (1997) Electronic fetal heart rate monitoring: research guidelines for interpretation. Am J Obstet Gynecol 177: 13851390.

6. Falkensammer CB, Paul J, Huhta JG (2001) Fetal congestive heart failure: correlation of Tei-index and Cardiovascular-score. J Perinat Med Ref 29: 390-398.

7. Kanzaki T, Chiba Y (1990) Evaluation of the preload 
condition of the fetus by inferior vena caval blood flow pattern. Fetal Diagn Ther 5: 168-174.

8. Stanley FL (2011) Reference Intervals for Laboratory Tests and Procedures. In: Kliegman RM, Stanton B, St.Geme J, Schor NF, Behrman RE (eds) Nelson Textbook of Pediatrics (19th Edition). Elsevier, Philadelphia, PA, pp 2466.

9. Matsuura N, Harada S, Ohyama Y, et al. (1997) The mechanisms of transient hypothyroxinemia in infants born to mothers with Graves' disease. Pediatr Res 42: 214-218.

10. Ranzini AC, Ananth CV, Smulian JC, Kung M, Limbachia A, et al. (2001) Ultrasonography of the fetal thyroid: nomograms based on biparietal diameter and gestational age. J Ultrasound Med 20: 613-617.

11. Tongsong $\mathrm{T}$, Wanapirak C, Kunavikatikul C, Sirirchotiyakul S, Piyamongkol W, et al. (2000) Cordocentesis at 16-24 weeks of gestation: experience of 1, 320 cases. Prenat Diagn 20: 224-228.

12. Srisupundit K, Sirichotiyakul S, Tongprasert F, Luewan S, Tongsong T (2008) Fetal therapy in fetal thyrotoxicosis: a case report. Fetal Diagn Ther 23: 114-116.

13. Polak M (2011) Thyroid disorders during pregnancy: impact on the fetus. Horm Res Paediatr 76: 97-101.

14. Emerson $\mathrm{CH}$, Anderson AJ, Howard WJ, Utiger RD (1975) Serum thyroxine and triiodothyronine concentrations during iodide treatment of hyperthyroidism. $J$
Clin Endocrinol Metab 40: 33-36.

15. Kubota S, Ohye H, Sasaki I, et al. (2005) Successful Use of Iodine and Levothyroxine to Treat Graves' Disease in a Pregnant Patient with Allergy to Antithyroid Drugs and High Thyrotropin-Binding Inhibitor Immunoglobulin After Radioiodine Therapy. Thyroid 15: 1373-1376.

16. Momotani N, Hisaoka $\mathrm{T}$, Noh J, Ishikawa $\mathrm{N}$, Ito $\mathrm{K}$ (1992) Effects of iodine on thyroid status of fetus versus mother in treatment of Graves' disease complicated by pregnancy. J Clin Endocrinol Metab 75: 738-744.

17. Momotani N, Noh J, Oyanagi H, Ishikawa N, Ito K (1986) Antithyroid drug therapy for Graves' disease during pregnancy. Optimal regimen for fetal thyroid status. N Engl J Med 315: 24-28.

18. Morine M, Takeda T, Minekawa R, Sugiyama T, Wasada $\mathrm{K}$, et al. (2002) Antenatal diagnosis and treatment of a case of fetal goitrous hypothyroidism associated with high-output cardiac failure. Ultrasound Obstet Gynecol 19: 506-509.

19. Hamada N, Momotani N, Ishikawa N, Yoshimura Noh J, Okamoto Y, et al. (2011) Persistent high TRAb values during pregnancy predict increased risk of neonatal hyperthyroidism following radioiodine therapy for refractory hyperthyroidism. Endocr J 58: 55-58.

20. Chan GW, Mandel SJ (2007) Therapy insight: management of Graves' disease during pregnancy. Nat Clin Pract Endocrinol Metab 3: 470-478. 